\title{
Home Energy Conservation, Monitoring and Corrective Techniques
}

\author{
M. Sangeetha, Balaji.S, John Paul Praveen A
}

\begin{abstract}
Energy conservation ensures that understanding the resources in the home, identifying the energy and waste of energy in the unwanted manner. More energy consumable products are identified and they are replaced with a less energy consumable products. The energy meter pattern also taken before and after the implementation of the corrective techniques. Always energy conservation is better than energy produced by the Generation. The optimal use of the equipments in the home has to be identified, analysed and implemented. To minimize the energy usage not only helps to conserve energy but also it helps to reduce the amount

Keywords:Power,Consumption,Condition.
\end{abstract}

\section{I.INTRODUCTION}

For country economic development, energy plays a vital role for the quality of life. The energy consumptions models were developed for buildings that are commercialized and also in residential houses to describe the household appliances with the characteristics or patterns. The equipment used reflects the behavior of the people and their life style.

The energy consumption is categorized into 4 fields: residential areas outside and inside municipality and small buildings outside and within municipality.

The equipments are categorized into category under Lighting: which includes fluorescent lamp and also incandescent lamp, category under cooking: electric kettle, microwave oven, electric rice cooker, electric stove, and juice blender. Category under Entertainment: stereo, radio and personal computer, TV, video player. Category under Amenity : electric water pump water heater, vacuum cleaner, air-conditioning, iron box, fan, washing machine, refrigerator.

Revised Manuscript Received on July 22, 2019

M. Sangeetha, ECE, Bharath Institute of Higher Education and Research,India. Email: sang_gok@yahoo.com

Balaji.S, ECE, Bharath Institute of Higher Education and Research,India. Email: bala.sripathy@gmail.com

John paul Praveen A, ECE,

\section{II.LITERATURE REVIEW}

The buildings with the share of $30 \%$ to $40 \%$ are the largest consumers of electrical energy.[8]. Different buildings sector includes commercial buildings large scale buildings, small scale buildings, and buildings for public are included in this building sector. The above buildings share electrical equipments and electronics equipments. Unfortunately, energy inefficiency operation is the main drawback in these buildings. 40-50 \% energy saving is applied to these buildings.

Energy Management System (EMS) is developed to control the inefficient energy equipments operations in buildings which provides the accountability for every energy consumption appliances used. EMS is the first step in saving energy. Each equipment is analyzed for its energy consumption to save more. Implementing efficient devices and methods, energy savings can be improved .

The common electrical equipments used in buildings are not that energy efficient. Control implementation and perfect conditions achievements is in its initial stage. Many devices with high energy efficiency are still available and due to improvements in technology like speed controlled fan, air conditioner and efficient lights. Its possible to conserve energy by implementing devices with high energy efficiency and efficient algorithms for controlling .

Inefficient conventional utilities like bulky fans, incandescent bulbs, air conditioners are still used in most of the residential buildings . Comparing with developed countries, usage of energy efficient fixtures are very less. Even educated people are not aware of the importance of energy efficient utilities for energy savings. The real estate sector is gaining its position because of increasing population growth. The fact is that the builders are not even aware of the importance of energy efficient buildings.

\section{III.METHODOLOGY}

Conventional utilities energy consumption must be compared with energy efficient utilities inorder to know about the energy savings offers gained by using energy efficient utilities. The Energy auditing before and after with different appliances are proposed to carry on our comparative study. We planned to minimize external effects on the system by comparing energy consumption.

Following table shows the before and after energy audit values. And it consist per day, month and year wise data. 
Table:1: Before and after energy audit data values

\begin{tabular}{|c|c|c|c|c|c|c|c|c|c|c|}
\hline & & & & AFTER ENI & ERGY AUDIT & & & & & \\
\hline S.NO & APPLIAANCES & WATT & NO'S & PER HOUR & USAGE HOUR & DAY(WATTS) & DAY(UNIT) & MONTH(UNIT) & YEAR(UNIT) & COST(Y@Rs.5) \\
\hline 1 & TUBELIGHT & 38 & 5 & 190 & 6 & 1140 & 1.14 & 34.2 & 416.1 & 2080.5 \\
\hline 2 & CEILING FAN & 53 & 3 & 159 & 8 & 1272 & 1.272 & 38.16 & 464.28 & 2321.4 \\
\hline 3 & CFL LAMP & 17 & 4 & 68 & 6 & 408 & 0.408 & 12.24 & 148.92 & 744.6 \\
\hline 4 & LED LAMP & 11 & 2 & 22 & 6 & 132 & 0.132 & 3.96 & 48.18 & 240.9 \\
\hline 5 & $\mathrm{AC}$ & 1780 & 1 & 1780 & 8 & 14240 & 14.24 & 427.2 & 5197.6 & 25988 \\
\hline 6 & LED TV & 75 & 1 & 75 & 8 & 600 & 0.6 & 18 & 219 & 1095 \\
\hline 7 & REFRIGERATOR & 183 & 1 & 183 & 4 & 732 & 0.732 & 21.96 & 267.18 & 1335.9 \\
\hline & & & & & & & & TOTAL & 6761.26 & 33806.3 \\
\hline & & & & BEFORE EI & NERGY AUDIT & & & & & \\
\hline S.NO & APPLIAANCES & WATT & NO'S & PER HOUR & USAGE HOUR & DAY(WATTS) & DAY(UNIT) & MONTH(UNIT) & YEAR(UNIT) & COST(Y@Rs.5) \\
\hline 1 & TUBELIGHT & 51 & 6 & 306 & 6 & 1836 & 1.836 & 55.08 & 670.14 & 3350.7 \\
\hline 2 & CEILING FAN & 100 & 4 & 400 & 8 & 3200 & 3.2 & 96 & 1168 & 5840 \\
\hline 3 & INCANDECENT LAMP & 60 & 6 & 360 & 6 & 2160 & 2.16 & 64.8 & 788.4 & 3942 \\
\hline 4 & $\mathrm{AC}$ & 2000 & 1 & 2000 & 8 & 16000 & 16 & 480 & 5840 & 29200 \\
\hline 5 & CRT TV & 80 & 1 & 80 & 8 & 640 & 0.64 & 19.2 & 233.6 & 1168 \\
\hline 6 & REFRIGERATOR & 270 & 1 & 270 & 4 & 1080 & 1.08 & 32.4 & 394.2 & 1971 \\
\hline & & & & & & & & TOTAL & 9094.34 & 45471.7 \\
\hline
\end{tabular}

\section{IV.RESULTS}

After Energy audit Graphical representation of appliance consumed cost per year. Plotted in X-axis appliance and $y$-axis cost.

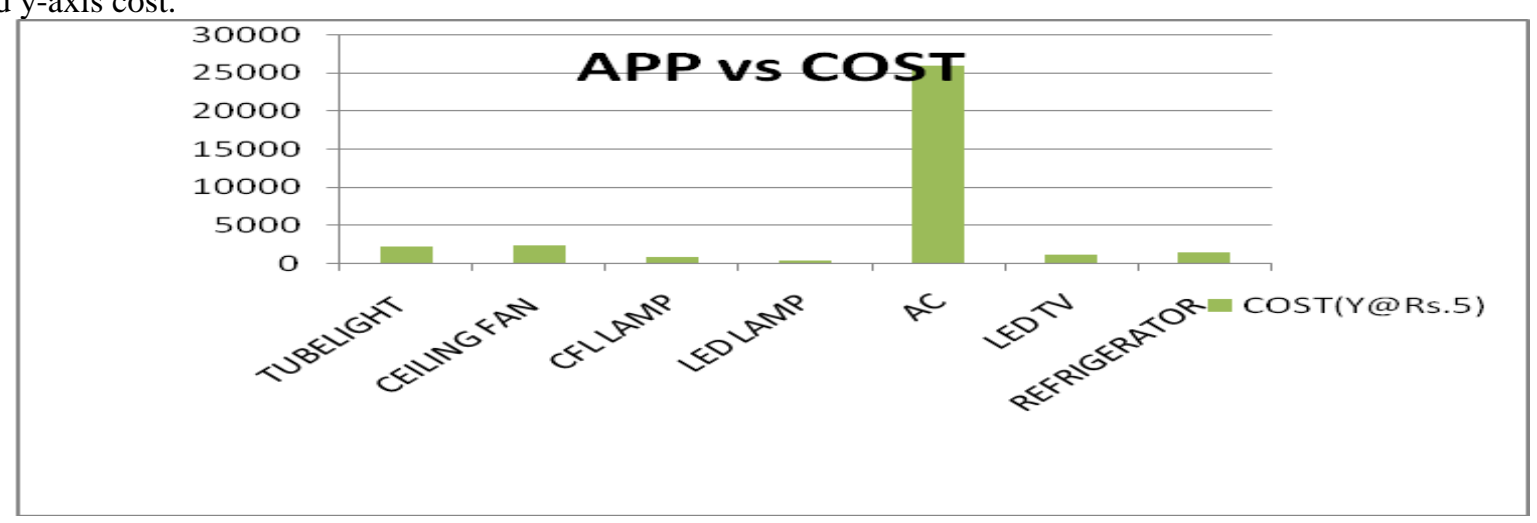

Fig 1: After Energy Audit Graphical Representation Of Appliance Consumed Unit Per Year. Plotted In $\mathrm{X}$-Axis Appliance And Y-Axis Unit.

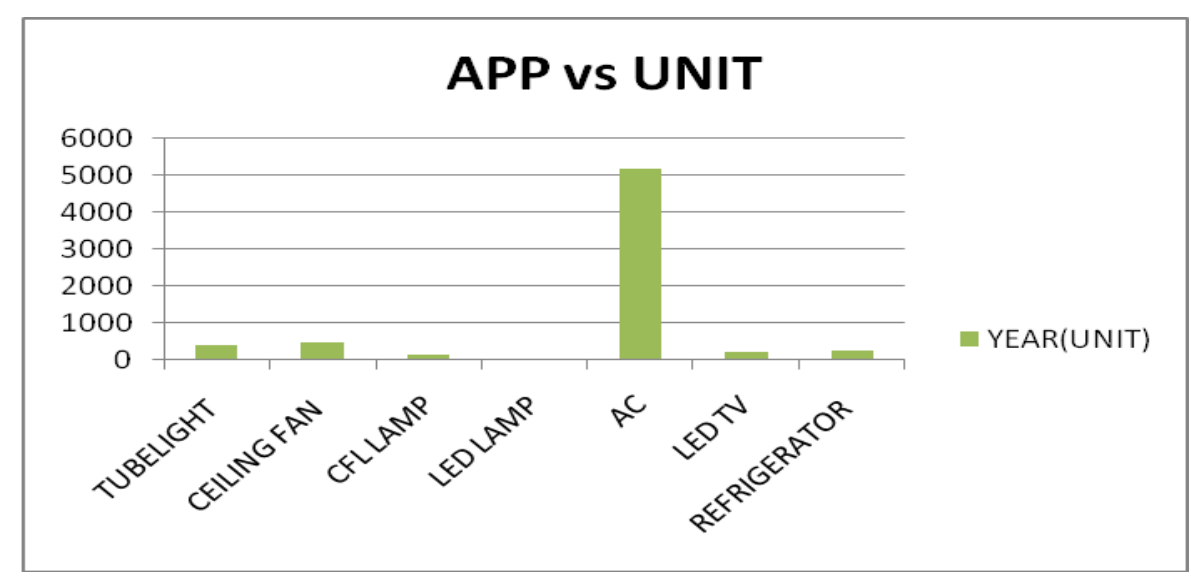

Fig 2: Before Energy audit Graphical representation of appliance consumed unit per year. Plotted in x-axis appliance and $\mathrm{y}$-axis cost. 


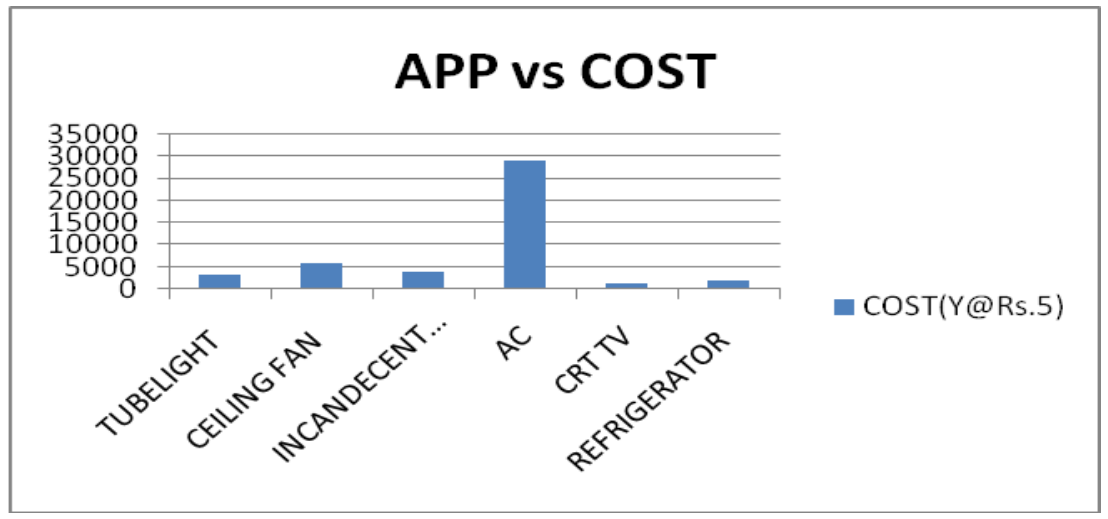

Fig 3: Before Energy audit Graphical representation of appliance consumed unit per year. Plotted in x-axis appliance and $y$-axis unit.

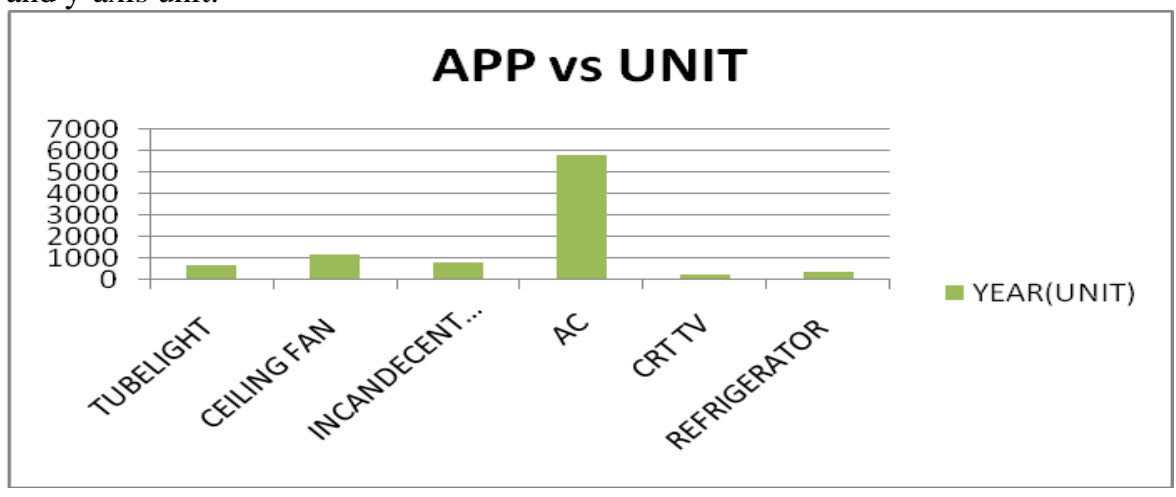

Fig 4:App Vs Unit

\section{CONCLUSION}

Tremendous improved results have acquired from the energy conservation through energy audit.

\section{REFERENCES}

[1] Bureau of energy efficiency guide books, book 1, chapter 03 "Energy Management and Audit", page no. 54-78.

[2] Sandip Ballal, "Energy Performance Important and Energy CostReductions at Baltic Place Commercial Office Complex", thesis published in STAFFORDSHIRE University, February 2016, page no.1-64

[3] Rakiba Rayhana, "Electric and Lighting Energy Audit: A Case Study ofSelective Commercial Buildings in Dhaka", 2015 IEEE international WIE conference on 20 December 2015, page no 1-4.

[4] Barney L. Capehart, "Guide to Energy Management", Book published by The Fairmont Press, Inc 2003, Chapter no 5 .

[5] Rajesh Tilwani, "Energy saving potentials in building through energy audit - A case study in an Indian building", published in 2015 IEEE International Conference on Technological Advancement in Power \& Energy, June 2015, page no 289-293.

[6] Sonal Desai, "Handbook of Energy Audit", Book published by McGraw Hill (India) Private Limited, 2015, chapter $1 \& 2$.

[7] Shailesh K. R., "Energy consumption optimization in classrooms using lighting energy audit", Research and technology in coming decades (CRT 2013), IEEE National Conference, 27-28 Sept. 2013, page no.1-5.

\section{AUTHORS PROFILE}

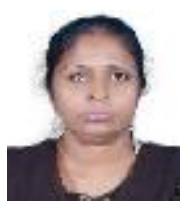

M. Sangeetha, ECE, Bharath Institute of Higher Education and Research,India

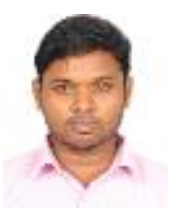

Balaji .S , Assistant Professor , ECE, Bharath Institute of Higher Education and Research,Chennai,India

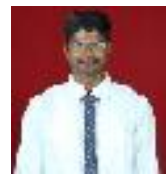

John Paul Praveen , Assistant Professor ,ECE, Bharath Institute of Higher Education and Research, Chennai,India. 